\title{
The genetic architecture of milk ELISA scores as an indicator of Johne's disease (paratuberculosis) in dairy cattle
}

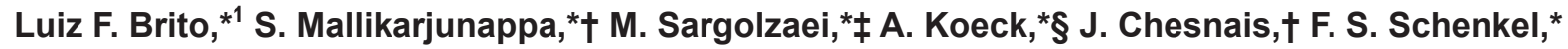 \\ K. G. Meade,† F. Miglior, *\# and N. A. Karrow* \\ ${ }^{*}$ Centre for Genetic Improvement of Livestock, Department of Animal Biosciences, University of Guelph, Guelph, N1G 2W1, Ontario, Canada \\ †Animal and Bioscience Research Department, Animal and Grassland Research and Innovation Centre, Teagasc, Grange, Co. Meath, Ireland \\ †The Semex Alliance, 20B Gervin Street, Ottawa, K2G 0J8, Ontario, Canada \\ $\S Z u c h t D a t a$ EDV-Dienstleistungen GmbH, A-1200, Vienna, Austria \\ \#Canadian Dairy Network, Guelph, N1K 1E5, Ontario, Canada
}

\section{ABSTRACT}

Johne's disease (or paratuberculosis), caused by $M y$ cobacterium avium ssp. paratuberculosis (MAP) infection, is a globally prevalent disease with severe economic and welfare implications. With no effective treatment available, understanding the role of genetics influencing host infection status is essential to develop selection strategies to breed for increased resistance to MAP infection. The main objectives of this study were to estimate genetic parameters for the MAP-specific antibody response using milk ELISA scores in Canadian Holstein cattle as an indicator of resistance to Johne's disease, and to unravel genomic regions and candidate genes significantly associated with MAP infection. After data editing, 168,987 milk ELISA records from 2,306 herds, obtained from CanWest Dairy Herd Improvement, were used for further analyses. Variance and heritability estimates for MAP infection status were determined using univariate linear animal models under 3 scenarios: (a) SCEN1: the complete data set (all herds); (b) SCEN2: herds with at least one suspect or test-positive animal (ELISA optical density $\geq 0.07$ ); and (c) SCEN3: herds with at least one test-positive animal (ELISA optical density $\geq 0.11$ ). Heritability estimates were calculated as $0.066,0.064$, and 0.063 for SCEN1, SCEN2, and SCEN3, respectively. The correlations between estimated breeding values for resistance to MAP infection and other economically important traits, when significant, were favorable and of low magnitude. Genomewide association analyses identified important genomic regions on Bos taurus autosome (BTA)1, BTA7, BTA9, BTA14, BTA15, BTA17, BTA19, and BTA25 showing significant association with MAP infection status.

Received December 5, 2017.

Accepted July 12, 2018.

${ }^{1}$ Corresponding author: lbrito@uoguelph.ca
These regions included 2 single nucleotide polymorphisms located $2 \mathrm{~kb}$ upstream of positional candidate genes $C D 86$ and $W N T 9 B$, which play key roles in host immune response and tissue homeostasis. This study revealed the genetic architecture of MAP infection in Canadian Holstein cattle as measured by milk ELISA scores by estimating genetic parameters along with the identification of genomic regions potentially influencing MAP infection status. These findings will be of significant value toward implementing genetic and genomic evaluations for resistance to MAP infection in Holstein cattle.

Key words: genetic parameter, genome-wide association study, paratuberculosis, milk ELISA, ruminant

\section{INTRODUCTION}

Johne's disease (JD), also referred to as paratuberculosis, is a contagious and chronic, progressive intestinal inflammatory disease caused by Mycobacterium avium ssp. paratuberculosis (MAP). Johne's disease is a major economic constraint for the global dairy industry and is a welfare issue (Geraghty et al., 2014). Economic losses caused by JD are associated with increased premature culling; diminished productive and reproductive performances; and reduced absorption of nutrients, which leads to reduced feed conversion efficiency; increased susceptibility to secondary infections, increased veterinary costs, and penalty payments due to reduced milk quality. Mycobacterium avium ssp. paratuberculosis has also been putatively associated with human Crohn's disease (Ott et al., 1999; Weber, 2006; Richardson and More, 2009; Atreya et al., 2014; Garcia and Shalloo, 2015), making it a potential zoonotic pathogen.

The epidemiology of JD is complex, and the clinical manifestations and economic impact of the disease in cattle can be variable depending on factors such as herd management, age, infection dose, and disease 
prevalence. No effective treatment for JD is currently available (Attalla et al., 2010). Johne's disease control programs, or voluntary pilot programs, have been implemented in various countries including Australia, Canada, Denmark, Iceland, Japan, the Netherlands, Norway, the United Kingdom, and the United States (Kennedy and Allworth, 2000; Groenendaal et al., 2003; Gunnarsson et al., 2003; Tharaldsen et al., 2003; Carter, 2011; Momotani, 2012; Geraghty et al., 2014; Garcia and Shalloo, 2015; Pieper et al., 2015). However, diagnosis of JD is difficult due to its long subclinical incubation period and the lack of sensitive diagnostic tests (Nielsen, 2008).

In the last decade, substantial research efforts have focused on development of vaccines to control JD (Bannantine et al., 2014); however, high-efficacy vaccines as well as effective treatments are still lacking; thus, alternative approaches to limit spread of JD are urgently needed. Evidence indicates genetic variability for resistance to MAP infection (Gonda et al., 2006; Küpper et al., 2012), demonstrating that genetic selection might be a feasible complementary approach to reduce or eliminate JD in dairy cattle. Genetic progress for disease resistance is a long-term process; however, the results are permanent and cumulative over generations.

To genetically select for JD resistance, several parameters need to be investigated such as heritability, genetic correlations with other economically important traits, and potential genomic regions and candidate genes associated with the trait need to be identified (Finlay et al., 2012; van Hulzen et al., 2014). Since 2005, CanWest DHI (www.canwestdhi.com; Guelph, Ontario, Canada) has offered MAP ELISA testing of milk samples to Canadian dairy producers, and a large test data set has been assembled that can be used to investigate the above parameters. Despite the fact that heritability estimates for JD have been previously reported, country-specific genetic parameter estimation is very valuable (van Hulzen et al., 2011; Küpper et al., 2012), and estimates in updated data sets always warrant calculation. Thus, the overall objective of this study was to investigate genetic and genomic aspects of resistance/susceptibility to JD. The specific objectives were to (1) estimate genetic parameters for JD in Canadian Holstein cattle using milk ELISA MAP test results from routinely collected milk samples, and 3 different scenarios; (2) investigate correlations between the sire EBV for MAP resistance and various economically important traits; (3) perform a genomewide association (GWAS) and functional analyses for JD to identify genetic markers and potential candidate genes associated with the disease for use in breeding programs; and (4) present a comprehensive literature review of heritability estimates and genomic regions significantly associated with JD in dairy cattle.

\section{MATERIALS AND METHODS}

\section{Phenotypic and Pedigree Data}

Milk samples were collected from lactating cows across their lactation cycle. Milk ELISA test results from March 2005 to June 2013 were obtained from CanWest DHI (www.canwestdhi.com). The applied ELISA test (AntelBio Milk ELISA, Antel BioSystems, Lansing, MI) measures the amount of MAP-specific antibody as optical density (OD) values, and was performed according to manufacturer's instructions (www.antelbio.com). In the present study, only animals between 19 and 200 mo of age at the time of ELISA testing were included in the analyses; as JD has a very long incubation period and older cows are, therefore, more likely to test positive than younger cows (Nielsen and Ersbøll, 2006).

Approximately $13 \%$ of cows had more than one ELISA test record, and because it is possible for an animal to become seropositive during the sampling period, a shift from MAP infection negative to MAP infection positive ELISA test may be observed. Likewise, it is also possible for an animal to go from MAP infection positive to MAP infection negative according to ELISA test results if it is not actively shedding MAP, or has become immunologically tolerant to MAP, making it a potential reservoir for MAP. Therefore, only one ELISA test result (the highest $\mathrm{OD}$ value) was considered for each cow. The final data set consisted of 168,987 ELISA test records from 2,306 herds. A pedigree file containing $1,349,303$ animals was generated by tracing back the pedigrees of cows with data up to 7 generations ago. For genetic analyses, the OD values of the ELISA test were transformed to correct for the nonnormal distribution of OD scores as follows: ELISA $_{\mathrm{T}}=\log _{\mathrm{e}}($ ELISA + 1 ), where ELISA is the OD value in the test.

\section{Estimation of Genetic Parameters}

Data were analyzed with univariate linear animal models using the average information-REML procedure in the derivative-free approach to multivariate analysis software (DMU v.6; Madsen and Jensen, 2008). To take into account within-herd exposure, variance components, heritabilities, and breeding values for MAP infection status were calculated for 3 scenarios using different subsets of data: (1) SCEN1: the complete data set (all herds), (2) SCEN2: herds with at least one suspect or test-positive animal (ELISA OD $\geq 0.07$ ), 
and (3) SCEN3: herds with at least one test-positive animal (ELISA OD $\geq 0.11$ ). In matrix notation, the model fitted was as follows:

$$
\mathbf{y}=\mathbf{X} \boldsymbol{\beta}+\mathbf{Z}_{\mathbf{h}} \mathbf{h}+\mathbf{Z}_{\mathrm{a}} \mathbf{a}+\mathbf{e}
$$

where $\mathbf{y}$ is a vector of observations; $\boldsymbol{\beta}$ is a vector of fixed age at test-date effects; $\mathbf{h}$ is a vector of random herd-year-season effects; $\mathbf{a}$ is a vector of random animal additive genetic effects; $\mathbf{e}$ is a vector of random residuals; and $\mathbf{X}, \mathbf{Z}_{\mathrm{h}}$, and $\mathbf{Z}_{\mathrm{a}}$ are the corresponding incidence matrices. Age at test-date had 6 classes: $\leq 24,>24$ to $36,>36$ to $48,>48$ to $60,>60$ to 72 , and $>72$ mo. Seasons were defined as January-March, April-June, July-September, and October-December. Maternal effects were not a significant source of variation $(P>$ $0.05)$ and, therefore, were not included in the models. Random effects were assumed to be normally distributed with zero mean, and $\operatorname{Var}(a)=\mathbf{A} \sigma_{a}^{2}, \operatorname{Var}(h)=\mathbf{I} \sigma_{h}^{2}$, $\operatorname{Var}(e)=\mathbf{I} \sigma_{e}^{2}$, where $\sigma_{a}^{2}, \sigma_{h}^{2}$, and $\sigma_{e}^{2}$ are the additive genetic, herd-year-season, and residual variances, respectively; $\mathbf{I}$ is an identity matrix; and $\mathbf{A}$ is the additive genetic relationship matrix. Heritability estimates were calculated as

$$
\sigma_{a}^{2} /\left(\sigma_{a}^{2}+\sigma_{h}^{2}+\sigma_{e}^{2}\right)
$$

The resulting EBV were reversed in sign: higher EBV indicate sires/dams with daughters more resistant to JD. Pearson correlations between JD EBV for sires with at least 30 daughters and their corresponding EBV for milk yield, SCS, calving to first service, 56-d nonreturn rate (cows), number of services (cows), first service to conception (cows), days open, direct herd life, overall feet and legs, and overall conformation were calculated with PROC CORR of SAS software (ver. 9.2, SAS Institute Inc., Cary, NC).

\section{Genotypic Data}

The Canadian Dairy Network (www.cdn.ca, Guelph, Ontario, Canada) provided pedigree, genotypes, and official evaluations for proven animals. Individuals were genotyped using the BovineHD SNP panel (HD, Illumina, San Diego, CA) or using a lower-density panel and accurately (Larmer et al., 2014) imputed to HD using the FImpute software (Sargolzaei et al., 2014). Genotype quality control was applied to exclude SNP located on nonautosomal regions of the genome or with unknown genome position, with very highly significant $\left(P<10^{-6}\right)$ Hardy-Weinberg equilibrium deviation, heterozygous excess $(>0.15)$, minor allele frequency
$(<0.01)$, and call rate $(<0.90)$. Animals with call rate lower than $90 \%$ were also excluded. The number of SNP and animals kept in the analyses was 294,064 and 3,455 , respectively.

\section{Genome-Wide Association and Functional Analyses}

Genome-wide association analysis was carried out by a mixed inheritance linear model, which included a single-SNP regression and an animal polygenic effect. Pseudo-phenotypes [i.e., de-regressed EBV calculated as in VanRaden (2008) for MAP infection status of the genotypes of animals $(3,455,3,173$, and 3,091 for SCEN1, SCEN2, and SCEN3, respectively)] were used as response variables. The linear model was

$$
\mathbf{y}=1 \boldsymbol{\mu}+\mathbf{b x}+\mathbf{Z a}+\mathbf{e}
$$

where $\mathbf{y}$ was the vector of pseudo-phenotypes for MAP infection status, $\mathbf{1}$ was a vector of ones, $\boldsymbol{\mu}$ was the general mean, $\mathbf{b}$ was the additive allele substitution effect of the SNP, $\mathbf{x}$ was the vector of allele dosages (coded as 0,1 , or 2 for $\mathrm{BB}, \mathrm{AB}$, and $\mathrm{AA}$, respectively), $\mathbf{Z}$ was the incidence matrix connecting additive polygenic effects to corresponding pseudo-phenotypes, a was the vector of additive polygenic effects, and e was the vector of random residuals. The model assumptions were as follows: a follows a normal distribution $N\left(\mathbf{0}, \mathbf{G} \sigma_{a}^{2}\right)$, in which $\mathbf{G}$ was the genomic relationship matrix (VanRaden, 2008), and $\sigma_{a}^{2}$ was the additive genetic variance for JD. For random residuals, it was assumed that $e \sim N\left(\mathbf{0}, \mathbf{W} \sigma_{e}^{2}\right)$, where $\sigma_{e}^{2}$ was the residual variance and W was the diagonal matrix containing weights for the pseudo-phenotypes (i.e., inverse of the corresponding reliabilities). Association analyses were performed using the snp1101 software (Sargolzaei, 2014).

To account for multiple tests, $5 \%$ and $1 \%$ chromosome-wise false discovery rate (FDR) were used to identify significant and highly significant associations, respectively. As additional information, the number of significant SNP at 10\% FDR threshold was also presented. For completeness, GWAS results using genome-wise FDR correction were also presented as Supplemental Figures S1 and S2 (https://doi.org/10.3168/jds.2017 -14250). The inflation factor $\lambda$ (Devlin and Roeder, 1999) and quantile-quantile plots were calculated to compare observed distributions of $-\log (P$-value $)$ to the expected distribution under the no association model for each trait.

The significant SNP were surveyed to their corresponding genes or to surrounding genes within a distance of $100 \mathrm{~kb}$ (i.e., $50 \mathrm{~kb}$ to each side). The 
Table 1. Descriptive statistics of the analyzed data (milk ELISA tests)

\begin{tabular}{lrrrrc}
\hline Item & Records, no. & Mean & SD & Minimum & Maximum \\
\hline Negative & 166,673 & -0.019 & 0.020 & -0.20 & 0.06 \\
Suspect & 450 & 0.083 & 0.011 & 0.07 & 0.10 \\
Positive & 1,864 & 0.561 & 0.491 & 0.11 & 3.00 \\
Total & 168,987 & -0.013 & 0.078 & -0.20 & 3.00 \\
\hline
\end{tabular}

window size was defined based on the levels of linkage disequilibrium in Holstein cattle reported by Sargolzaei et al. (2008) for SNP pairs with less than $100 \mathrm{~kb}$ apart, which was about 0.58 (measure as allelic $\mathrm{r}^{2}$ ). Functional analyses were performed using the Ensembl Genome Browser (Ensembl, 2017), the Database for Annotation, Visualization and Integrated Discovery (DAVID) v6.8, BioMart (www.ensembl.org/biomart), and the National Center for Biotechnology Information database (NCBI, 2017).

\section{RESULTS AND DISCUSSION}

\section{Data and Descriptive Analysis}

Table 1 presents the descriptive statistics of the analyzed data. Approximately 98.63, 0.27 , and $1.10 \%$ of animals were tested as negative, suspect, and positive, respectively. The mean $( \pm \mathrm{SD})$ ELISA OD values were $-0.019 \pm 0.020,0.083 \pm 0.011,0.561 \pm 0.491$, and $-0.013 \pm 0.078$, for negative, suspect, positive, and all animals, respectively. The majority of ELISA OD values ranged from -0.06 to -0.02 (Supplemental Table S1; https://doi.org/10.3168/jds.2017-14250). Of the 2,306 herds represented in the study, 741 herds $(32 \%)$ had at least one suspect or positive-tested animal (Table 2). The frequency of test-positive animals was $1.1 \%$ in the complete data set and was slightly higher if only herds with at least one suspect or positive tested cow were considered (2.1\%). Tiwari et al. (2006) reviewed prevalence of MAP infections based on serum ELISA tests in different Canadian provinces and reported frequencies in the range of $1.3 \%$ (Prince Edward Island) to $7.0 \%$ (Alberta). The ELISA OD $\geq 0.11$ records were considered as positive tests. Attalla et al. (2010) reported that using a 0.1 threshold level gives a specificity of $99 \%$ and an overall sensitivity to MAP infection of $50 \%$, indicating the appropriateness of the chosen threshold. It is important to note that commercial companies providing ELISA test kits set the threshold value at which a cow is declared positive at different levels. The ELISA OD values were log-transformed to approximate a normal distribution. This is supported by previous studies that reported higher heritability estimates and more robust parameter estimates when using logtransformed ELISA OD values compared with treating OD values as a positive/negative binary trait for MAP status (Hinger et al., 2008; Attalla et al., 2010). As shown in Table 2, the frequency of test-positive animals increased with age and was around $4.0 \%$ for cows older than 60 mo from positive herds (Table 2), which is in agreement with the literature (Hinger et al., 2008).

Diagnosis of JD has been attempted through various techniques such as serum and milk ELISA, fecal bacterial culture and PCR, antigen skin testing, IFN- $\gamma$ assays, bacteriophage analysis, newly identified MAPspecific antigens, host protein expression in response to infection, transcriptomic studies, analysis of microR$\mathrm{NA}$, and investigation of the gastrointestinal microbiome (Garcia and Shalloo, 2015; Britton et al., 2016; Pritchard et al., 2017a,b). In this study, the bovine antibody-mediated immune response was measured as an indicator of MAP exposure by milk ELISA; this test is most commonly used for detection of MAP-

Table 2. Percentage of cows with a positive milk ELISA test result (ELISA optical density value $\geq 0.11$ )

\begin{tabular}{|c|c|c|c|c|c|c|}
\hline \multirow{2}{*}{$\begin{array}{l}\text { Age in months } \\
\text { at test date }\end{array}$} & \multicolumn{2}{|c|}{$\begin{array}{c}\text { All herds } \\
(\mathrm{n}=2,306 \text { herds })\end{array}$} & \multicolumn{2}{|c|}{$\begin{array}{l}\text { Suspect or positive herds } \\
\quad(\mathrm{n}=741 \text { herds })\end{array}$} & \multicolumn{2}{|c|}{$\begin{array}{l}\text { Positive herds } \\
(\mathrm{n}=630 \text { herds })\end{array}$} \\
\hline & Records, no. & Frequency, \% & Records, no. & Frequency, \% & Records, no. & Frequency, \% \\
\hline$>24$ to 36 & 47,650 & 0.4 & 25,288 & 0.8 & 22,243 & 0.9 \\
\hline$>36$ to 48 & 42,805 & 0.9 & 22,477 & 1.8 & 19,781 & 2.0 \\
\hline$>48$ to 60 & 30,714 & 1.5 & 16,213 & 2.8 & 14,320 & 3.2 \\
\hline All & 168,987 & 1.1 & 87,940 & 2.1 & 77,469 & 2.4 \\
\hline
\end{tabular}


Table 3. Estimates of variances (multiplied by 10,000) and heritability

\begin{tabular}{|c|c|c|c|c|c|c|}
\hline Parameter & \multicolumn{2}{|c|}{ All herds } & \multicolumn{2}{|c|}{ Suspect or positive herds } & \multicolumn{2}{|c|}{ Positive herds } \\
\hline Additive genetic variance $\left(\sigma_{a}^{2}\right)$ & 2.780 & 0.186 & 4.700 & 0.444 & 5.100 & 0.519 \\
\hline Herd-year-season variance $\left(\sigma_{h}^{2}\right)$ & 14.700 & 0.433 & 22.400 & 1.020 & 23.200 & 1.140 \\
\hline Residual variance $\left(\sigma_{e}^{2}\right)$ & 24.700 & 0.161 & 46.900 & 0.403 & 53.100 & 0.479 \\
\hline
\end{tabular}

${ }^{1}$ Heritability: $h^{2}=\sigma_{a}^{2} /\left(\sigma_{a}^{2}+\sigma_{h}^{2}+\sigma_{e}^{2}\right)$.

specific antibodies in infected animals, for estimation of prevalence, and for disease control programs (Garcia and Shalloo, 2015). In addition, the test is cost-effective and simple to perform with a quick turnaround time as compared with detection by culture. Consequently, it is more practical for producers as more records are available for genetic evaluations. However, the drawback of this method is its low sensitivity $(30 \%)$ that may not allow for detection during the early phase of infection and could yield erroneous false-negative results.

\section{Estimation of Genetic Parameters}

This study estimated genetic parameters for the presence of a MAP-specific antibody response in milk of Canadian Holstein cows based on milk ELISA test results. Estimates of variance components and heritability estimates are shown in Table 3, and they provide information about the role of host genetics in influencing MAP infection status as determined by milk ELISA tests. Besides the genetic capacity of the animal to resist MAP infection, a higher level of exposure to MAP increases the likelihood of becoming infected (Gonda et al., 2006). Therefore, as described earlier, we investigated 3 different scenarios, based on disease incidence in the herds and observed nearly identical heritability estimates in all the 3 data sets. The heritability estimates were $0.066 \pm 0.004,0.064 \pm 0.006$, and $0.063 \pm$ 0.006 for SCEN1, SCEN2, and SCEN3, respectively. In addition to similar heritability estimates among all 3 scenarios, EBV of sires for resistance to JD in all 3 data sets, having at least 30 daughters, were highly correlated ( $>0.95$, Table 4$)$, indicating that breeding values from any of the 3 scenarios investigated could be used for selection in breeding programs. However, similar findings have not been observed in other populations. For instance, van Hulzen et al. (2011) reported heritability estimates ranging from 0.031 for the complete data set to 0.097 for herds with a minimum within-herd test prevalence of at least $10 \%$.

As shown in Table 5, studies performed in other populations have also reported that MAP infection status is under genetic control with heritability estimates ranging from 0.03 to 0.27 . Differences among these studies may be due to many factors such as various diagnostic tests, variable disease incidence in the studied populations, different management practices, the population under investigation (as genetic parameters are population-specific), trait definitions, statistical models, pedigree depth, data editing, and others. In our study, maternal effects were not a significant source of variation $(P>0.05)$ and, therefore, were not included in the statistical models; this is in agreement with other studies that reported contribution of maternal effects to JD phenotypic variance lower than 1.5\% (Mortensen et al., 2004; Attalla et al., 2010; Pritchard et al., 2017a).

\section{Correlations with Other Traits}

Correlations among sire EBV for resistance to MAP infection and official genomic breeding values of various economically important traits are given in Table 6; higher EBV for routinely evaluated traits in Canada are considered favorable, the exception being SCC. A higher genetic merit for milk yield was not associated with higher susceptibility to MAP infection. In general,

Table 4. Correlations of EBV for all 3 scenarios (SCEN) including only EBV from sires with at least 30 daughters for resistance to Johne's disease (above diagonal) or including only EBV from genotyped bulls (below diagonal)

\begin{tabular}{lccc}
\hline Scenario & All herds & Suspect or positive herds & Positive herds \\
\hline All herds (SCEN1) & & 0.970 & 0.960 \\
Suspect or positive herds (SCEN2) & 0.964 & 0.996 & 0.990 \\
Positive herds (SCEN3) & 0.947 & 0.996 \\
\hline
\end{tabular}




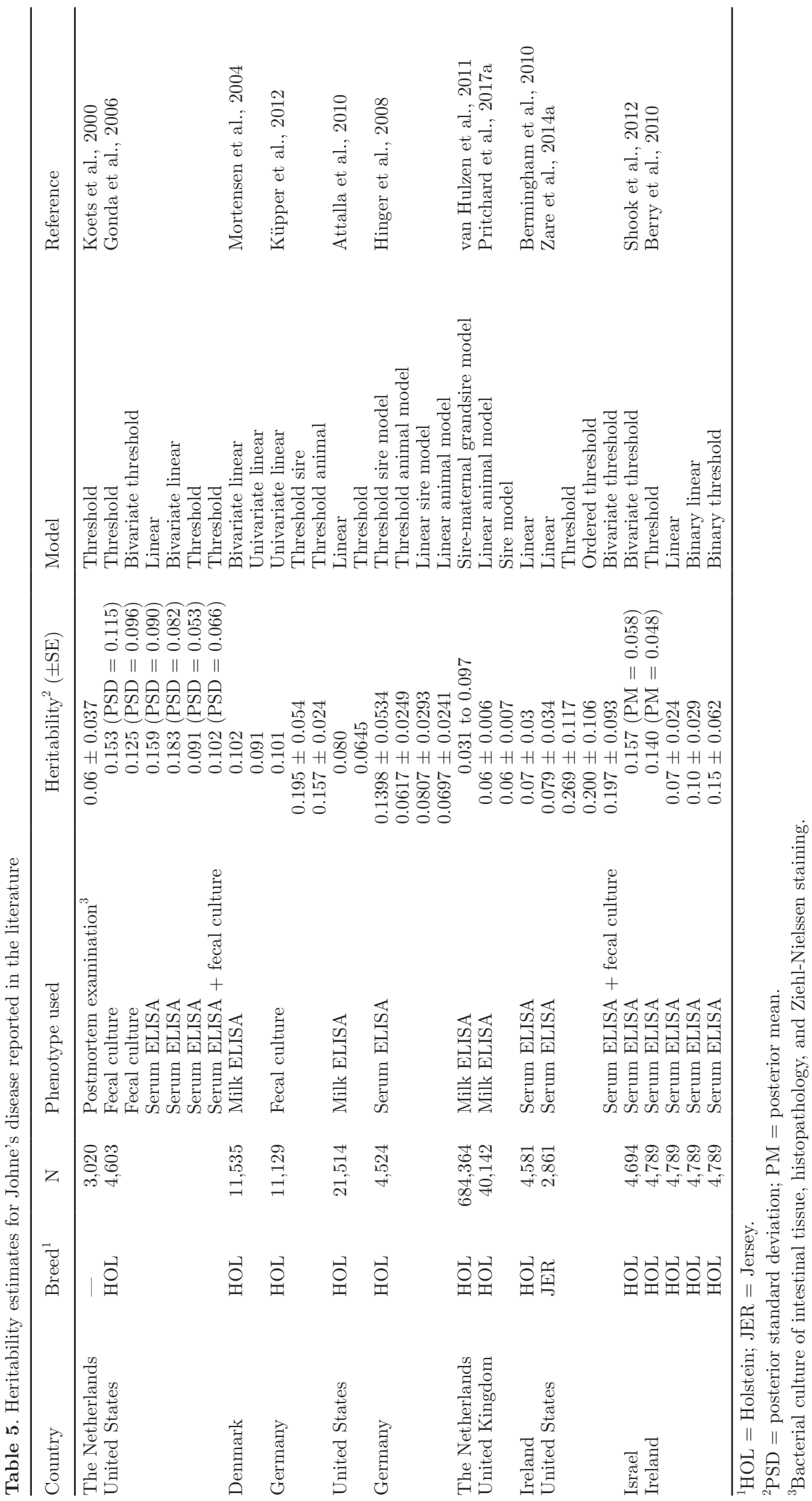


there is no clear consensus in the literature regarding milk production traits; however, most correlations, when significant, are of low magnitude. For instance, Mortensen et al. (2004) observed a genetic correlation near zero $(-0.037)$ with daily milk yield, and Pritchard et al. (2017a) reported favorable, but generally weak, genetic correlations with 305-d milk yield $(-0.16)$, 305d protein yield $(-0.16), \log _{\mathrm{e}}$-transformed lactation-average SCC (0.15), and the number of mastitis episodes (0.22). Considering MAP serological response as both a binary and a continuous trait, Berry et al. (2010) reported negative and significant genetic correlations, and negative but not different from zero correlation between MAP serological response and yield traits, respectively. In another study, Attalla et al. (2010) reported a nonsignificant correlation between MAP milk ELISA scores and milk yield, whereas for fat $(-0.20)$ and protein yield $(-0.18)$ correlations were significant and negative. With regards to udder health traits, Pritchard et al. (2017a) reported significant positive genetic correlations between milk antibody response and udder health traits such as log-transformed SCC and number of mastitis episodes, implying that animals predisposed to higher SCC or mastitis may also mount a higher antibody response during MAP infection; therefore, selection for lower MAP antibody response could be favorable for udder health. Shook et al. (2012) reported unfavorable genetic correlations that ranged from 0.14 to 0.22 for MAP infection with milk production traits; however, these estimates were associated with high confidence intervals that also contained zero values.

Desirable significant antagonistic correlations between MAP infection status and calving to first service and longevity were observed in our study (Table 6), implying that selection for these traits could reduce susceptibility to MAP infection (as measured by milk ELISA). Pritchard et al. (2017a) reported that genetic correlations between MAP antibody response and different fertility traits were low, negative, and not significant. Additionally, Berry et al. (2010) found low, nonsignificant correlations between MAP serological response and calving interval and perinatal mortality. In the context of longevity, a higher culling rate among cows testing positive for MAP infection is expected (Hendrick et al., 2005; Smith et al., 2010).

Similar to calving-to-first-service and longevity traits, favorable correlations were also observed for traits such as overall score for feet and legs and overall score for conformation (Table 6). Attalla et al. (2010) observed statistically significant negative correlations of productive life and net merit with sire breeding values for OD value and Kudahl and Nielsen (2009) found that slaughter weight and value were reduced by 10 and $17 \%$, respectively, for ELISA-positive cows compared with test-negative cows.

\section{GWAS and Functional Analyses}

To better understand the genetic basis of MAP infection status, we also performed a GWAS aiming to identify genomic regions significantly associated with the trait. As shown in Figures 1 and 2 (Manhattan plots) and Table 7 and Supplemental Table S2 (https://doi .org/10.3168/jds.2017-14250), various chromosomal regions were significantly associated with MAP infection status. The most significant peaks were located on chromosomes BTA1, BTA15, BTA17, and BTA19. The total number of significant SNP identified at a chromosome-wise FDR of 1,5 , and $10 \%$ was 0,45 , and 176 for SCEN2, respectively, and 7, 73, and 232 for SCEN3, respectively. The GWAS were performed only for SCEN2 and SCEN3, as SCEN1 also included data from herds in which the infectious agent might not have been present (i.e., animals were not disease challenged). The majority of genomic regions significantly associ-

Table 6. Estimated breeding value correlations between Johne's disease and other routinely evaluated traits ( $\mathrm{n}=$ sires with at least 30 daughters for resistance to Johne's disease)

\begin{tabular}{lccc}
\hline Trait & $\begin{array}{c}\text { All herds } \\
(\mathrm{n}=813 \text { sires })\end{array}$ & $\begin{array}{c}\text { Suspect or positive herds } \\
(\mathrm{n}=351 \text { sires })\end{array}$ & $\begin{array}{c}\text { Positive herds } \\
(\mathrm{n}=319 \text { sires })\end{array}$ \\
\hline Milk yield, kg & -0.07 & -0.08 & -0.09 \\
SCS & -0.03 & -0.06 & -0.04 \\
Calving to first service, $\mathrm{d}$ & $0.09^{*}$ & $0.11^{*}$ & 0.10 \\
56-d nonreturn rate, cows & -0.01 & -0.01 & -0.01 \\
Number of services, cows & 0.02 & 0.02 & 0.03 \\
First service to conception, cows & 0.04 & 0.07 & 0.07 \\
Days open & 0.06 & 0.10 & 0.09 \\
Direct herd life, d & $0.12^{* *}$ & $0.19^{* * *}$ & $0.18^{* *}$ \\
Overall feet and legs & $0.14^{* * *}$ & $0.26^{* * *}$ & $0.26^{* * *}$ \\
Overall conformation & $0.15^{* * *}$ & $0.25^{* * *}$ & $0.25^{* * *}$ \\
\hline
\end{tabular}

Significant correlations: ${ }^{*} P<0.05,{ }^{* *} P<0.01,{ }^{* * *} P<0.001$. 


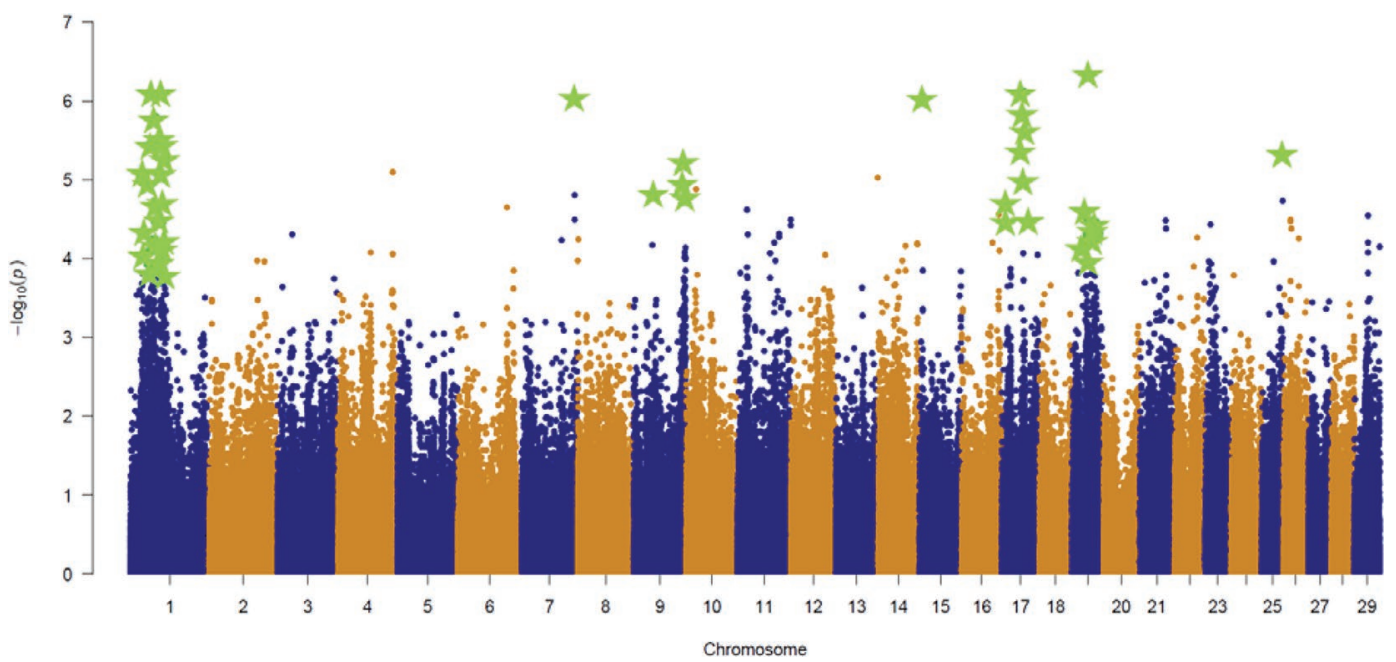

Figure 1. Manhattan plot for milk ELISA positivity for Mycobacterium avium ssp. paratuberculosis (MAP)-specific antibodies (as an indicator of resistance to Johne's disease) using data only from herds that had at least one positive cow (scenario 3). Stars represent significant markers at $5 \%$ chromosome-wise false discovery rate. Color version available online.

ated with JD were identified in both GWAS scenarios. However, no significant markers at $1 \%$ FDR were identified in SCEN2, which indicates that the inclusion of only positive herds (SCEN3) might have provided more power to detect significant associations. Figure 3 presents the $-\log (P$-value $)$ estimates for the markers significantly associated with JD in both SCEN2 and SCEN3 at a $10 \%$ chromosome-wise FDR (which includes all significance levels). The results indicate that the large majority of markers were identified by both scenarios.

Supplemental Figures S1 and S2 (https://doi.org/10 $.3168 /$ jds.2017-14250) present the markers significantly associated with JD at 5\% genome-wise FDR correction. The peaks on BTA1, BTA7, BTA14, BTA15, BTA17, and BTA19 were also detected when using a genomewise FDR threshold. As expected, in this case the number of genomic regions identified was smaller compared with the chromosome-wise FDR correction. However, the main objective of using chromosome-wise FDR is to be less strict (and, therefore, to have more power to detect associations), but at the same time to account for the fact that there are more hypothesis tests in chromosomes with more markers (usually the longer ones). By applying FDR correction at the chromosome

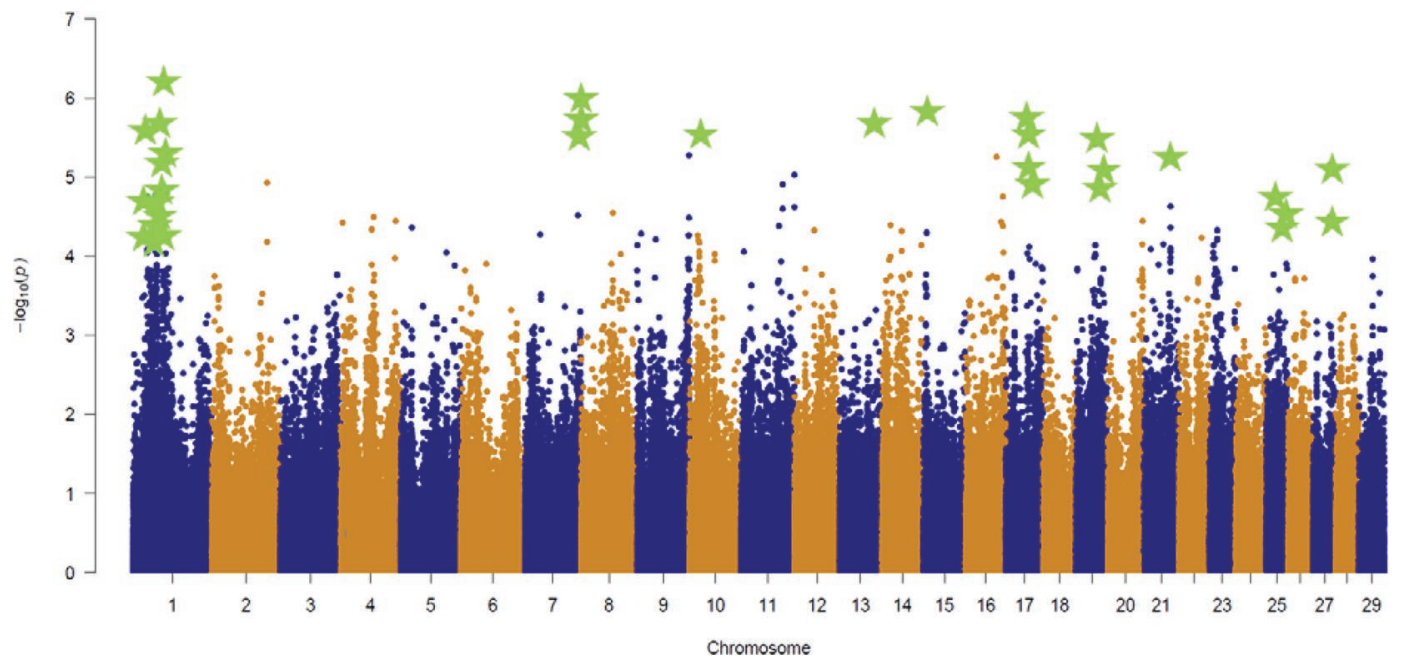

Figure 2. Manhattan plot for milk ELISA positivity for Mycobacterium avium ssp. paratuberculosis (MAP)-specific antibodies (as indicator of resistance to Johne's disease) using data from herds that had at least one suspect or positive cow (scenario 2). Stars represent significant markers at $5 \%$ chromosome-wise false discovery rate. Color version available online. 
level, we account for the number of tests within each chromosome and, therefore, we keep the same FDR level across the whole genome.

Quantile-quantile plots comparing the observed distribution of $-\log (P$-value $)$ to the expectation under null hypothesis are shown in Figure 4. The plots show a distribution relatively close to the expected distribution line for SCEN2 $\left(\lambda_{\text {median }}=1.1937\right.$ and $\lambda_{\text {mean }}$ $=1.1413)$ and $\operatorname{SCEN} 3\left(\lambda_{\text {median }}=1.1873\right.$ and $\lambda_{\text {mean }}=$ 1.1341), indicating no issue of population substructure or cryptic relatedness inflating $P$-values. As discussed by Nayeri et al. (2016), when an HD panel is used in single marker-association analysis, a large number of markers in linkage disequilibrium may potentially display association (and similar low $P$-values) with the same QTL region; this yields many significant tests that are not independent and, therefore, deviate from the expected distribution of test statistics. However, this does not imply inflation of $P$-values. As discussed by Yang et al. (2011), in the cases where there is a large inflation of $P$-values, it should be accounted for. Thus, corrected $P$-values would be used for FDR correction.

Table 7 also presents a list of candidate genes $(\mathrm{n}=$ 59) either containing significant SNP or within $200 \mathrm{~kb}$ of the immediate surrounding genomic region of the significantly associated SNP. For instance, the gene ALCAM (activated leukocyte cell adhesion molecule) has been associated with immunological synapses [Gene
Ontology (GO):0001772] and the T-cell receptor complex (GO:0042101), and the genes NFATC2IP (nuclear factor of activated T-cells 2 interacting protein) and ENSBTAG00000032122 (CD19 molecule) were also related to important functions such as cell signaling during the immune response (GO:0006968). In addition, IDO1 (indoleamine 2,3-dioxygenase 1) has been associated with cytokine production involved in the inflammatory response (GO:0002534) and positive regulation of the induction of T-cell tolerance (GO:0002666), chronic inflammatory response (GO:0002678), type 2 immune response (GO:0002830), inflammatory response (GO: 0006954), and regulation of apoptosis (GO:0043065).

Two SNP (rs134528210 and rs41922558) that were associated with MAP infection status were $2 \mathrm{~kb}$ upstream of positional candidate genes CD86 and $W N T 9 B$, respectively. The co-stimulatory molecule CD86 is expressed on antigen-presenting cells, such as macrophages and dendritic cells, and initiates and maintains CD4+ T-cell activation and proliferation (Vasilevko et al., 2002; Lim et al., 2012). In the context of JD, activation of $\mathrm{CD} 4^{+} \mathrm{T}$-cells by antigen-presenting cells is critical in eliciting a cellular adaptive immune response to clear MAP infection during the early stages of JD pathogenesis (Coussens, 2001). Chen et al. (2009) have reported pro-inflammatory induction properties of $C D 86$ where they observed increased expression of CD86 along with the proliferation of $\mathrm{CD}^{+}$and $\mathrm{CD} 8^{+}$

Table 7. Number of markers significantly associated with susceptibility/resistance to Johne's disease at $0.01,0.05$, and 0.10 chromosomewise false discovery rate (FDR) for scenario (SCEN) 2 (suspect or positive herds) and SCEN3 (positive herds) and candidate genes harboring significant markers

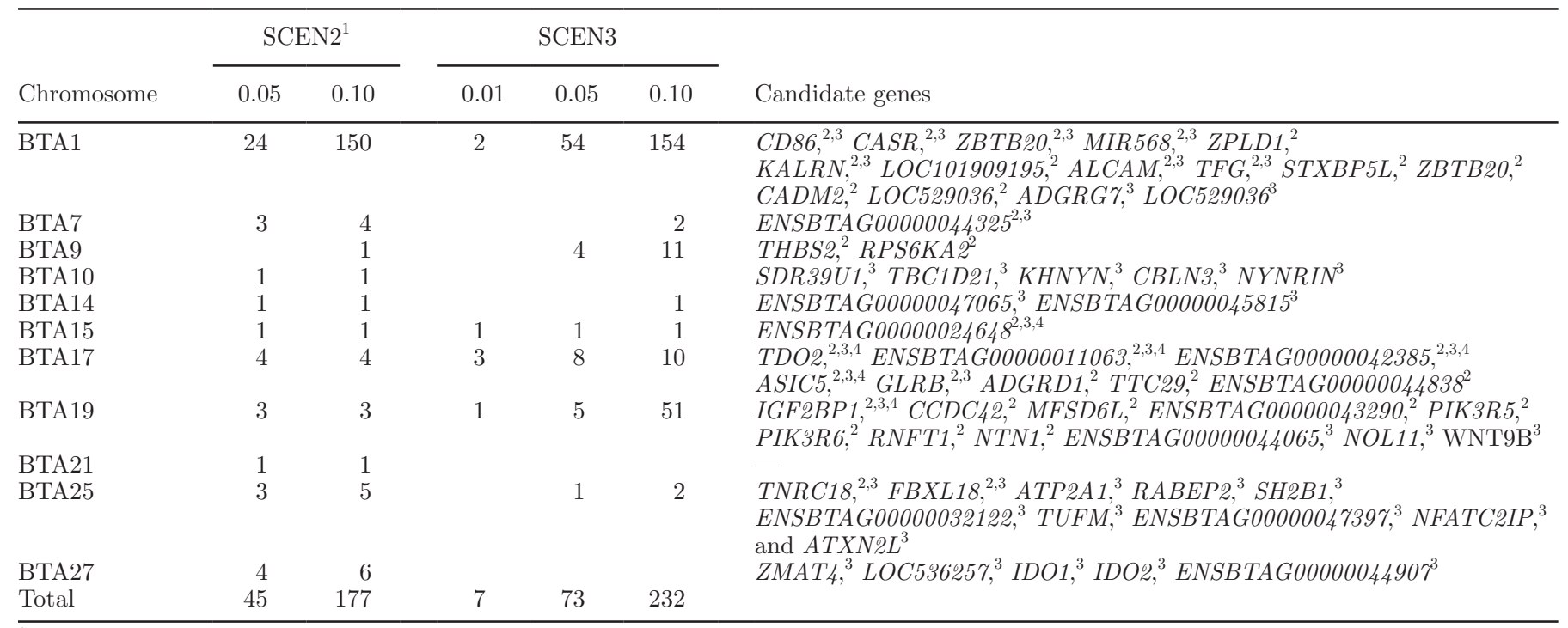

${ }^{1}$ There were no significant SNP at $1 \%$ FDR.

${ }^{2} \mathrm{SCEN} 3$ and $5 \%$ FDR.

${ }^{3} \mathrm{SCEN} 2$ and $5 \%$ FDR.

${ }^{4} \mathrm{SCEN} 3$ and $1 \%$ FDR. 


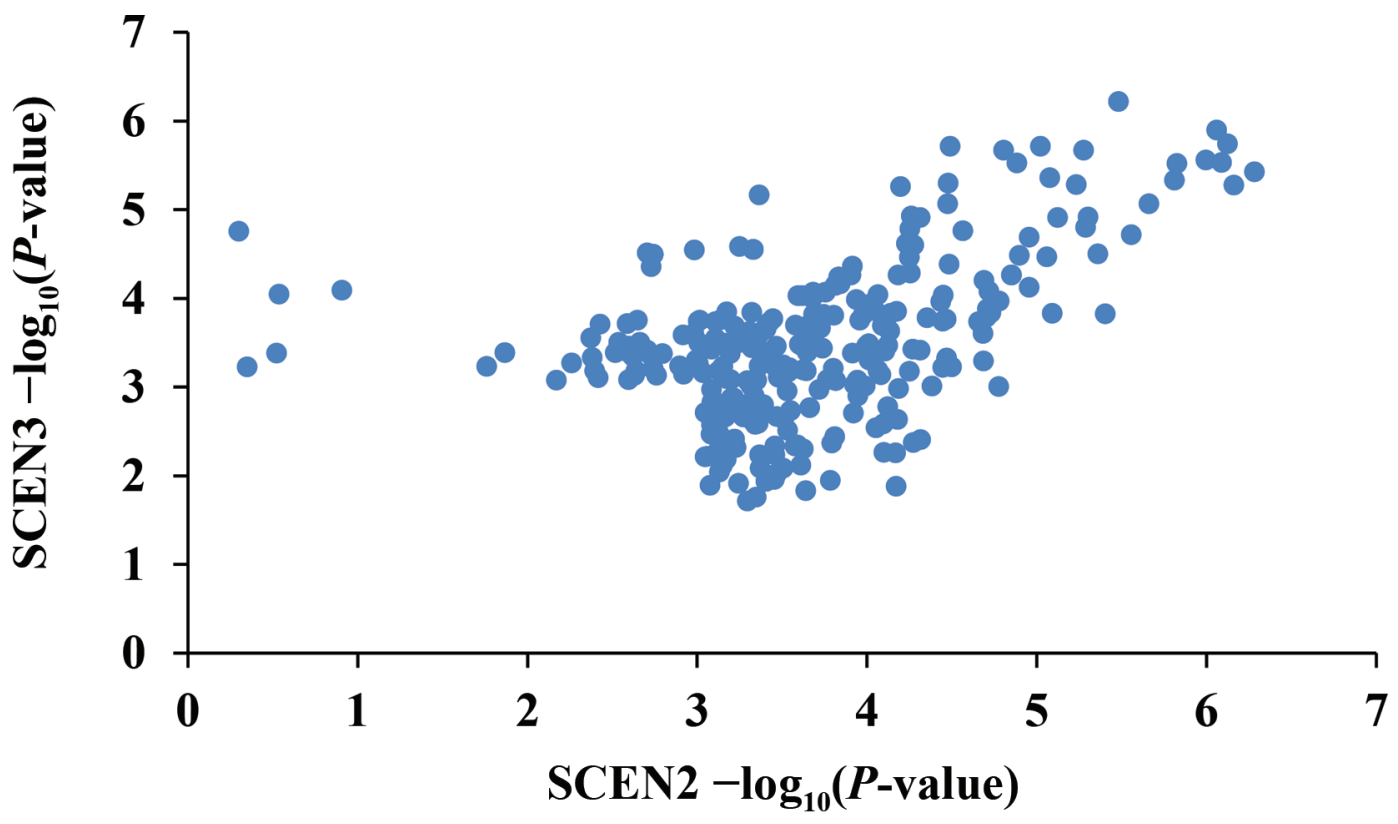

Figure 3. Plot of the $-\log _{10}(P$-value) estimates for the significant SNP (at all significance level thresholds considered in this study, i.e., up to $10 \%$ false discovery rate correction) identified in either SCEN2 or SCEN3 scenarios. Color version available online.

T cells in the intestinal mucosa of patients with Crohn's disease, a human inflammatory bowel disease. Some other SNP (rs43243282, rs43243290, rs43243293, and rs43243295) present in the CD86 intron region were also found to be significantly associated in this study.

The rs41922558 SNP is positioned $2 \mathrm{~kb}$ upstream of the functional candidate gene $W N T 9 B$. This gene belongs to the Wingless-type MMTV integration site gene family, and the association of members of this gene fam- ily with JD is well documented. For instance, Pauciullo et al. (2015) reported a significant association of SNP (rs43390642) in the WNT2 promoter region with JD susceptibility. In addition, van Hulzen et al. (2011) reported the presence of WNT2 gene within the identified QTL on BTA4 and its possible association with JD. Members of WNT gene family, through the $\beta$-catenin signaling pathway, play a role in fibrosis and tissue homeostasis (Guo et al., 2012). Määttänen et al. (2013)
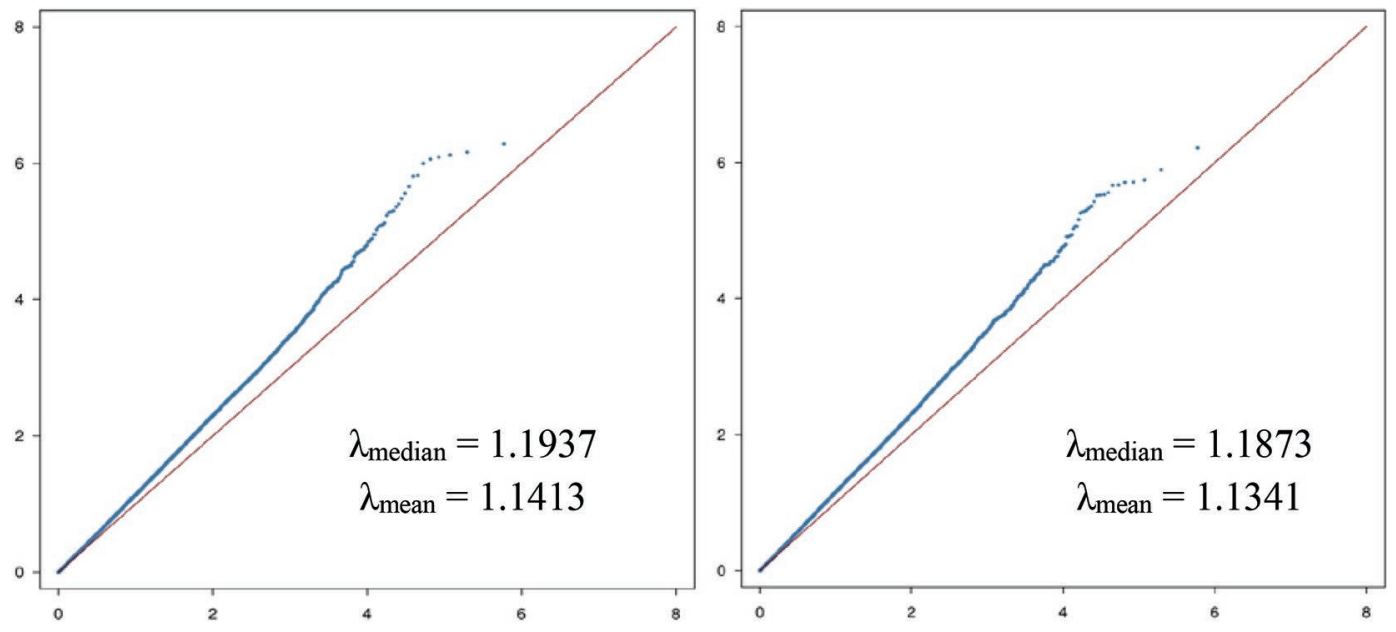

Figure 4. Quantile-quantile plot for association with milk ELISA positivity for Mycobacterium avium ssp. paratuberculosis (MAP)-specific antibodies [as indicator of resistance to Johne's disease; SCEN2 and SCEN3 scenarios in the left and right, respectively]. The straight line (red) shows the expected distribution of $P$-values; the dotted line (blue) shows the observed distribution of $P$-values. Color version available online. 


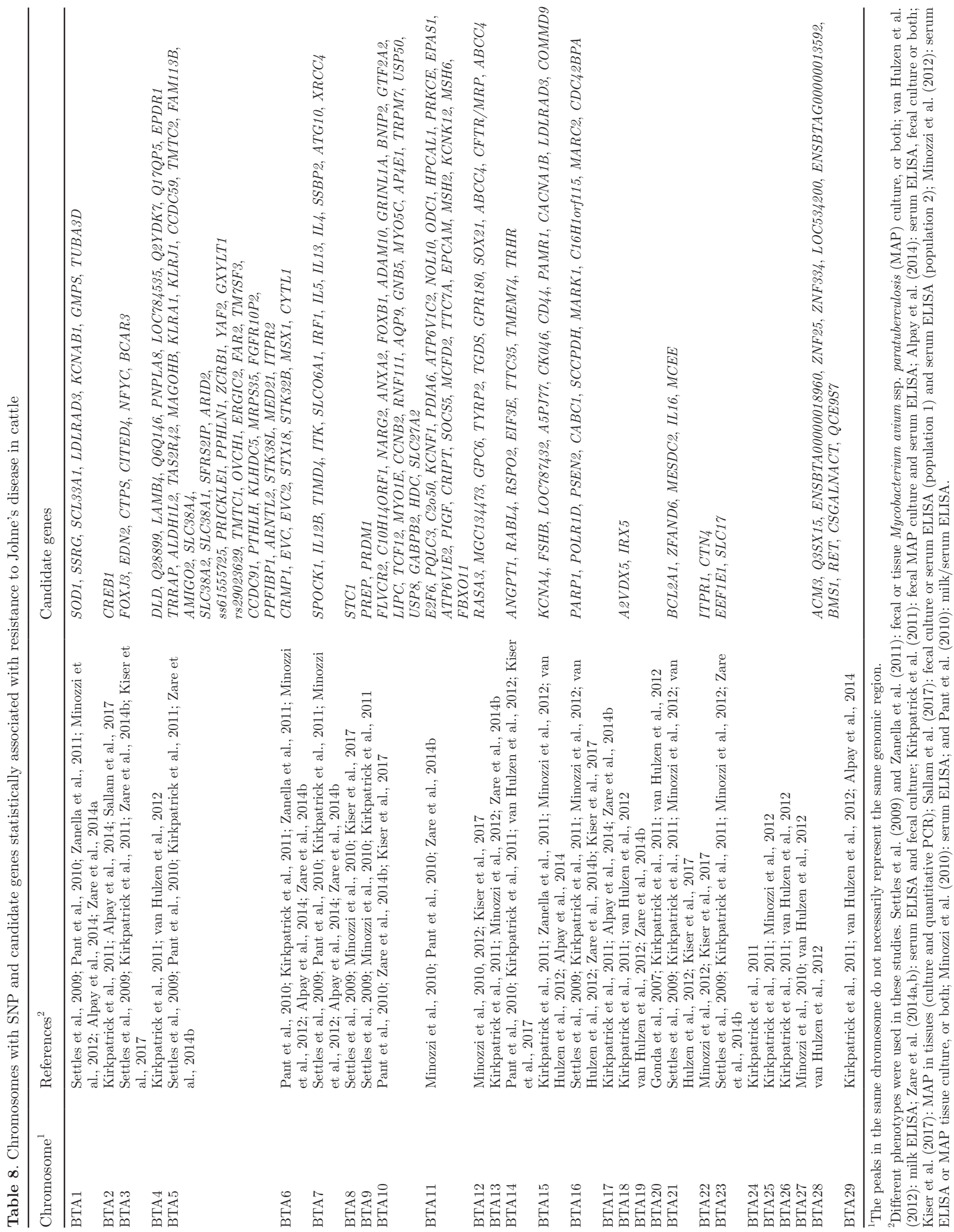


reported differential kinome responses associated with the WNT- $\beta$-catenin signaling pathway in calf ileal tissues at the site of MAP infection. Given the arbitrary assumption that the putative promoter region lies $2 \mathrm{~kb}$ upstream of transcription start site of a gene (Sinnett et al., 2006), it is possible that both rs134528210 and rs41922558 SNP lie within promoter regions and could regulate gene function. However, these are only assumptions and future studies should aim to characterize and validate the functional relevance of these SNP, and indeed the gene with respect to JD. This could be achieved by candidate-gene validation studies and gene editing approaches.

Table 8 shows a list of previous studies that identified significant peaks in various chromosomal regions over the genome that were associated with JD. The fact that a large number of significant regions have been identified in most chromosomes indicates that JD is a very polygenic trait. The little congruence with other studies might be due to differences in case definition (i.e., methods used in defining infected and healthy cohorts), statistical methodologies, the low heritability of the trait, the analysis of different populations, and the use of different genetic markers (Settles et al., 2009; Minozzi et al., 2010; Pant et al., 2010; van Hulzen et al., 2012). The significant regions identified in the present study, in conjunction with other ones already reported in the literature (Table 8), convey very useful information to potentially optimize genomic predictions to select for resistance to MAP infection, as significant markers can be included in customized SNP panels to increase accuracy of genomic breeding values for JD resistance.

\section{CONCLUSIONS}

This study estimated genetic parameters, and a GWAS was performed, based on the presence of MAPspecific antibody in milk of Canadian Holstein cows. Despite the low heritability estimates, significant genetic variation was observed, indicating that genetic progress can be made in North American Holstein cattle. The heritability estimates and breeding values calculated based on 3 alternate data sets, which considered different disease incidences, were similar, indicating that estimated breeding values from any of the data sets could be used for selection. The correlations between JD and other economically important traits were weak or not significant, suggesting that selection for resistance to MAP infection will not negatively affect other economically important traits in dairy cattle. Chromosomal regions involved in MAP-specific antibody response in milk were also identified. They confirmed that JD is a complex, polygenic trait. Similar analyses, but using different phenotypes, will be performed next to validate these results.

\section{ACKNOWLEDGMENTS}

We thank Canwest DHI for providing the milk ELISA data, and the following funding organizations for supporting the graduate and postdoctoral fellows who carried out the data analysis: The Semex Alliance, NSERC, the Teagasc Walsh Fellowship, and the Conselho Nacional de Desenvolvimento Científico e Tecnológico (CNPq/Brazil).

\section{REFERENCES}

Alpay, F., Y. Zare, M. H. Kamalludin, X. Huang, X. Shi, G. E. Shook, M. T. Collins, and B. W. Kirkpatrick. 2014. Genome-wide association study of susceptibility to infection by Mycobacterium avium subspecies paratuberculosis in Holstein cattle. PLoS One 9:e111704.

Atreya, R., M. Bülte, G.-F. Gerlach, R. Goethe, M. W. Hornef, H. Köhler, J. Meens, P. Möbius, E. Roeb, and S. Weiss. 2014. Facts, myths and hypotheses on the zoonotic nature of Mycobacterium avium subspecies paratuberculosis. Int. J. Med. Microbiol. 304:858867.

Attalla, S., A. Seykora, J. Cole, and B. Heins. 2010. Genetic parameters of milk ELISA scores for Johne's disease. J. Dairy Sci. 93:1729-1735.

Bannantine, J. P., M. E. Hines, I. I. Leb, A. M. Talaat, S. Sreevatsan, J. R. Stabel, Y.-F. Chang, P. M. Coussens, R. G. Barletta, and W. C. Davis. 2014. A rational framework for evaluating the next generation of vaccines against Mycobacterium avium subspecies paratuberculosis. Front. Cell. Infect. Microbiol. 4:126. https://doi .org/10.3389/fcimb.2014.00126.

Bermingham, M., S. More, M. Good, A. Cromie, P. Mullowney, I. Higgins, and D. Berry. 2010. Genetic associations between Johne's disease and susceptibility to Mycobacterium bovis and Mycobacterium avium subsp avium in Irish Holstein Friesian dairy cows. Adv. Animal Biol. 1:302.

Berry, D., M. Good, P. Mullowney, A. Cromie, and S. More. 2010. Genetic variation in serological response to Mycobacterium avium subspecies paratuberculosis and its association with performance in Irish Holstein-Friesian dairy cows. Livest. Sci. 131:102-107.

Britton, L. E., J. P. Cassidy, J. O'Donovan, S. V. Gordon, and B. Markey. 2016. Potential application of emerging diagnostic techniques to the diagnosis of bovine Johne's disease (paratuberculosis). Vet. J. 209:32-39.

Carter, M. A. 2011. State, federal, and industry efforts at paratuberculosis control. Vet. Clin. North Am. Food Anim. Pract. 27:637-645.

Chen, A., F. Li, J. Du, Y. Zhang, E. Gong, and X. Shi. 2009. Expression of co-stimulatory molecule CD86 and its inducible co-stimulator in Crohn disease and their pathologic significance. J. Peking Univ. Health Sci. 41:620-624.

Coussens, P. M. 2001. Mycobacterium paratuberculosis and the bovine immune system. Anim. Health Res. Rev. 2:141-161.

Devlin, B., and K. Roeder. 1999. Genomic control for association studies. Biometrics 55:997-1004.

Ensembl. 2017. Ensembl Genome Browser. Accessed Jul. 15, 2017. https://www.ensembl.org/ index.html.

Finlay, E. K., D. P. Berry, B. Wickham, E. P. Gormley, and D. G. Bradley. 2012. A genome-wide association scan of bovine tuberculosis susceptibility in Holstein-Friesian dairy cattle. PLoS One $7: \mathrm{e} 30545$

Garcia, A., and L. Shalloo. 2015. Invited review: The economic impact and control of paratuberculosis in cattle. J. Dairy Sci. 98:50195039 . 
Geraghty, T., D. A. Graham, P. Mullowney, and S. J. More. 2014. A review of bovine Johne's disease control activities in 6 endemically infected countries. Prev. Vet. Med. 116:1-11.

Gonda, M., Y. Chang, G. Shook, M. Collins, and B. Kirkpatrick. 2006. Genetic variation of Mycobacterium avium ssp. paratuberculosis infection in US Holsteins. J. Dairy Sci. 89:1804-1812.

Gonda, M., B. Kirkpatrick, G. Shook, and M. Collins. 2007. Identification of a QTL on BTA20 affecting susceptibility to Mycobacterium avium ssp. paratuberculosis infection in US Holsteins. Anim. Genet. 38:389-396.

Groenendaal, H., M. Nielen, and J. W. Hesselink. 2003. Development of the Dutch Johne's disease control program supported by a simulation model. Prev. Vet. Med. 60:69-90.

Gunnarsson, E., V. Fridriksdottir, and S. Sigurdarson. 2003. Control of paratuberculosis in Iceland. Acta Vet. Scand. 44:255.

Guo, Y., L. Xiao, L. Sun, and F. Liu. 2012. Wnt/[beta]-catenin signaling: A promising new target for fibrosis diseases. Physiol. Res. $61: 337$

Hendrick, S. H., D. F. Kelton, K. E. Leslie, K. D. Lissemore, M. Archambault, and T. F. Duffield. 2005. Effect of paratuberculosis on culling, milk production, and milk quality in dairy herds. J. Am. Vet. Med. Assoc. 227:1302-1308.

Hinger, M., H. Brandt, and G. Erhardt. 2008. Heritability estimates for antibody response to Mycobacterium avium subspecies paratuberculosis in German Holstein cattle. J. Dairy Sci. 91:3237-3244.

Kennedy, D., and M. Allworth. 2000. Progress in national control and assurance programs for bovine Johne's disease in Australia. Vet. Microbiol. 77:443-451

Kirkpatrick, B., X. Shi, G. Shook, and M. Collins. 2011. Whole-genome association analysis of susceptibility to paratuberculosis in Holstein cattle. Anim. Genet. 42:149-160.

Kiser, J., S. White, K. Johnson, J. Hoff, J. Taylor, and H. Neibergs 2017. Identification of loci associated with susceptibility to Mycobacterium avium subspecies paratuberculosis (MAP) tissue infection in cattle. J. Anim. Sci. 95:1080.

Koets, A., G. Adugna, L. Janss, H. Van Weering, C. Kalis, G. Wentink, V. Rutten, and Y. Schukken. 2000. Genetic variation of susceptibility to Mycobacterium avium ssp. paratuberculosis infection in dairy cattle. J. Dairy Sci. 83:2702-2708.

Kudahl, A. B., and S. S. Nielsen. 2009. Effect of paratuberculosis on slaughter weight and slaughter value of dairy cows. J. Dairy Sci. 92:4340-4346.

Küpper, J., H. Brandt, K. Donat, and G. Erhardt. 2012. Heritability estimates for Mycobacterium avium subspecies paratuberculosis status of German Holstein cows tested by fecal culture. J. Dairy Sci. 95:2734-2739.

Larmer, S., M. Sargolzaei, and F. S. Schenkel. 2014. Extent of linkage disequilibrium, consistency of gametic phase, and imputation accuracy within and across Canadian dairy breeds. J. Dairy Sci. 97:3128-3141.

Lim, T. S., J. K. H. Goh, A. Mortellaro, C. T. Lim, G. J. Hämmerling, and P. Ricciardi-Castagnoli. 2012. CD80 and CD86 differentially regulate mechanical interactions of T-cells with antigen-presenting dendritic cells and B-cells. PLoS One 7:e45185.

Määttänen, P., B. Trost, E. Scruten, A. Potter, A. Kusalik, P. Griebel, and S. Napper. 2013. Divergent immune responses to Mycobacterium avium ssp. paratuberculosis infection correlate with kinome responses at the site of intestinal infection. Infect. Immun. 81:2861-2872

Madsen, P., and J. Jensen. 2008. An User's Guide to DMU: A package for analysing multivariate mixed models. Version 6 , release 4.7 . Aarhus University, Foulum, Denmark.

Minozzi, G., L. Buggiotti, A. Stella, F. Strozzi, M. Luini, and J. L. Williams. 2010. Genetic loci involved in antibody response to Mycobacterium avium ssp. paratuberculosis in cattle. PLoS One 5:e11117.

Minozzi, G., J. L. Williams, A. Stella, F. Strozzi, M. Luini, M. L. Settles, J. F. Taylor, R. H. Whitlock, R. Zanella, and H. L. Neibergs. 2012. Meta-analysis of two genome-wide association studies of bovine paratuberculosis. PLoS One 7:e32578.
Momotani, E. 2012. Epidemiological situation and control strategies for paratuberculosis in Japan. Jpn. J. Vet. Res. 60(Suppl):S19S29.

Mortensen, H., S. S. Nielsen, and P. Berg. 2004. Genetic variation and heritability of the antibody response to Mycobacterium avium subspecies paratuberculosis in Danish Holstein cows. J. Dairy Sci. $87: 2108-2113$

Nayeri, S., M. Sargolzaei, M. K. Abo-Ismail, N. May, S. P. Miller, F. S. Schenkel, S. S. Moore, and P. Stothard. 2016. Genome-wide association for milk production and female fertility traits in Canadian dairy Holstein cattle. BMC Genet. 17:75.

NCBI. 2017. National Center for Biotechnology Information (2017). Accessed Jul. 13, 2017. https://www.ncbi.nlm.nih.gov/.

Nielsen, S. S. 2008. Transitions in diagnostic tests used for detection of Mycobacterium avium ssp. paratuberculosis infections in cattle. Vet. Microbiol. 132:274-282.

Nielsen, S. S., and A. K. Ersbøll. 2006. Age at occurrence of Mycobacterium avium subspecies paratuberculosis in naturally infected dairy cows. J. Dairy Sci. 89:4557-4566.

Ott, S. L., S. J. Wells, and B. A. Wagner. 1999. Herd-level economic losses associated with Johne's disease on US dairy operations. Prev. Vet. Med. 40:179-192.

Pant, S. D., F. S. Schenkel, C. P. Verschoor, Q. You, D. F. Kelton, S. S. Moore, and N. A. Karrow. 2010. A principal component regression based genome wide analysis approach reveals the presence of a novel QTL on BTA7 for MAP resistance in Holstein cattle. Genomics 95:176-182.

Pauciullo, A., J. Küpper, H. Brandt, K. Donat, L. Iannuzzi, and G. Erhardt. 2015. Wingless-type MMTV integration site family member 2 (WNT2) gene is associated with resistance to MAP in faecal culture and antibody response in Holstein cattle. Anim. Genet. $46: 122-132$

Pieper, L., U. S. Sorge, T. J. DeVries, A. Godkin, K. Lissemore, and D. F. Kelton. 2015. Evaluation of the Johne's disease risk assessment and management plan on dairy farms in Ontario, Canada. J. Dairy Sci. 98:6792-6800.

Pritchard, T., R. Mrode, M. Coffey, K. Bond, and E. Wall. 2017a. The genetics of antibody response to paratuberculosis in dairy cattle. J. Dairy Sci. 100:5541-5549.

Pritchard, T. C., M. P. Coffey, K. S. Bond, M. R. Hutchings, and E. Wall. 2017b. Phenotypic effects of subclinical paratuberculosis (Johne's disease) in dairy cattle. J. Dairy Sci. 100:679-690.

Richardson, E., and S. J. More. 2009. Direct and indirect effects of Johne's disease on farm and animal productivity in an Irish dairy herd. Ir. Vet. J. 62:526.

Sallam, A. M., Y. Zare, F. Alpay, G. E. Shook, M. T. Collins, S. Alsheikh, M. Sharaby, and B. W. Kirkpatrick. 2017. An acrossbreed genome wide association analysis of susceptibility to paratuberculosis in dairy cattle. J. Dairy Res. 84:61-67.

Sargolzaei, M. 2014. SNP1101 User's Guide. Version 1.0. HiggsGene Solutions Inc., Guelph, Canada.

Sargolzaei, M., J. P. Chesnais, and F. S. Schenkel. 2014. A new approach for efficient genotype imputation using information from relatives. BMC Genomics 15:478.

Sargolzaei, M., F. S. Schenkel, G. B. Jansen, and L. R. Schaeffer. 2008. Extent of linkage disequilibrium in Holstein cattle in North America. J. Dairy Sci. 91:2106-2117.

Settles, M., R. Zanella, S. McKay, R. Schnabel, J. Taylor, R. Whitlock, Y. Schukken, J. Van Kessel, J. Smith, and H. Neibergs. 2009. A whole-genome association analysis identifies loci associated with Mycobacterium avium ssp. paratuberculosis infection status in US Holstein cattle. Anim. Genet. 40:655-662.

Shook, G., M. Chaffer, X. L. Wu, and E. Ezra. 2012. Genetic parameters for paratuberculosis infection and effect of infection on production traits in Israeli Holsteins. Anim. Genet. 43:56-64.

Sinnett, D., P. Beaulieu, H. Bélanger, J.-F. Lefevre, S. Langlois, M.-C. Théberge, S. Drouin, C. Zotti, T. J. Hudson, and D. Labuda. 2006. Detection and characterization of DNA variants in the promoter regions of hundreds of human disease candidate genes. Genomics $87: 704-710$. 
Smith, R., R. Strawderman, Y. Schukken, S. Wells, A. Pradhan, L. Espejo, R. Whitlock, J. Van Kessel, J. Smith, and D. Wolfgang. 2010. Effect of Johne's disease status on reproduction and culling in dairy cattle. J. Dairy Sci. 93:3513-3524.

Tharaldsen, J., B. Djønne, B. Fredriksen, O. Nyberg, and O. Siguroardottir. 2003. The national paratuberculosis program in Norway. Acta Vet. Scand. 44:243-246.

Tiwari, A., J. A. VanLeeuwen, S. L. McKenna, G. P. Keefe, and H. W. Barkema. 2006. Johne's disease in Canada: Part I: Clinical symptoms, pathophysiology, diagnosis, and prevalence in dairy herds. Can. Vet. J. 47:874.

van Hulzen, K., A. Koets, M. Nielen, H. Heuven, J. van Arendonk, and D. Klinkenberg. 2014. The effect of genetic selection for Johne's disease resistance in dairy cattle: Results of a genetic-epidemiological model. J. Dairy Sci. 97:1762-1773.

van Hulzen, K., M. Nielen, A. Koets, G. de Jong, J. van Arendonk, and H. Heuven. 2011. Effect of herd prevalence on heritability estimates of antibody response to Mycobacterium avium subspecies paratuberculosis. J. Dairy Sci. 94:992-997.

van Hulzen, K., G. Schopen, J. van Arendonk, M. Nielen, A. Koets, C. Schrooten, and H. Heuven. 2012. Genome-wide association study to identify chromosomal regions associated with antibody response to Mycobacterium avium subspecies paratuberculosis in milk of Dutch Holstein-Friesians. J. Dairy Sci. 95:2740-2748.

VanRaden, P. M. 2008. Efficient methods to compute genomic predictions. J. Dairy Sci. 91:4414-4423.
Vasilevko, V., A. Ghochikyan, M. J. Holterman, and M. G. Agadjanyan. 2002. CD80 (B7-1) and CD86 (B7-2) are functionally equivalent in the initiation and maintenance of $\mathrm{CD} 4+\mathrm{T}$-cell proliferation after activation with suboptimal doses of PHA. DNA Cell Biol. $21: 137-149$.

Weber, M. F. 2006. Risk management of paratuberculosis in dairy herds. Ir. Vet. J. 59:555.

Yang, J., M. N. Weedon, S. Purcell, G. Lettre, K. Estrada, C. J. Willer, A. V. Smith, E. Ingelsson, J. R. O'connell, M. Mangino, and R. Mägi. 2011. Genomic inflation factors under polygenic inheritance. Eur. J. Hum. Genet. 19:807.

Zanella, R., M. Settles, S. McKay, R. Schnabel, J. Taylor, R. Whitlock, Y. Schukken, J. Van Kessel, J. Smith, and H. Neibergs. 2011. Identification of loci associated with tolerance to Johne's disease in Holstein cattle. Anim. Genet. 42:28-38.

Zare, Y., G. Shook, M. Collins, and B. Kirkpatrick. 2014a. Heritability estimates for susceptibility to Mycobacterium avium subspecies paratuberculosis infection defined by ELISA and fecal culture test results in Jersey cattle. J. Dairy Sci. 97:4562-4567.

Zare, Y., G. Shook, M. T. Collins, and B. W. Kirkpatrick. 2014b. Genome-wide association analysis and genomic prediction of $M y-$ cobacterium avium subspecies paratuberculosis infection in US Jersey cattle. PLoS One 9:e88380. 